\title{
HUBUNGAN PENGETAHUAN DENGAN CAKUPAN K4 PADA IBU HAMIL DI PUSKESMAS SANGKUNUR
}

\author{
Lena Juliana Harahap \\ STIKes Darmais Padangsidimpuan \\ e-mail: lenajulianahrp@gmail.com
}

\begin{abstract}
Antenatal Care $(A N C)$ is a planned program in the form of observation, education and medical treatment for pregnant women to obtain a safe and satisfying process of pregnancy and childbirth. ANC visits should be done at least 4 times during pregnancy, namely $K 1$ to $K 4$, with a time distribution of at least 1 time in the first trimester (0-12 weeks of gestation), at least 1 time in the second trimester (12-24 weeks of gestation), and at least 2 times in the third trimester (24 weeks gestation - birth). This type of research is an analytic study with a cross sectional design. The population in this study were all 124 pregnant women in the final third semester of Sangkunur Health Center using simple random sampling of 95 people. Data obtained from the Sangkunur Health Center and through the results of interviews using a questionnaire. The data analysis method was analyzed by univariate, bivariate using the Chi-square test. Based on the results of statistical tests with the Chi-square test, it is known that there is a relationship between knowledge and $K 4$ coverage in pregnant women $(0.006<0.05)$. It is recommended to Sangkunur Health Center to regularly provide outreach to pregnant women about the importance of conducting antenatal care visits in order to get antenatal care services so that pregnant women can visit health service places. Keywords: Knowledge, K4 coverage
\end{abstract}

\begin{abstract}
ABSTRAK
Antenatal Care (ANC)/Asuhan antenatal adalah suatu program yang terencana berupa observasi, edukasi dan penanganan medik pada ibu hamil, untuk memperoleh suatu proses kehamilan dan persalinan yang aman dan memuaskan. Kunjungan ANC sebaiknya dilakukan sekurang-kurangnya 4 kali selama kehamilan yaitu K1 sampai dengan K4, dengan distribusi waktu minimal 1 kali pada trimester pertama (usia kehamilan 0-12 minggu), minimal 1 kali pada trimester kedua (usia kehamilan 12-24 minggu), dan minimal 2 kali pada trimester ketiga (usia kehamilan 24minggu - lahir). Jenis penelitian yang digunakan adalah studi analitik dengan desain cross sectional. Populasi dalam penelitian ini adalah seluruh ibu hamil rimester III akhir yang ada di Puskesmas Sangkunur sebanyak 124 orang dengan menggunakan simple random sampling 95 orang. Data diperoleh dari Puskesmas Sangkunur dan melalui hasil wawancara dengan menggunakan kuesioner. Metode analisa data dianalisis secara univariat, bivariat dengan menggunakan uji Chisquare. Berdasarkan hasil uji statistik dengan uji Chisquare, diketahui bahwa ada hubungan antara pengetahuan dengan cakupan K4 pada ibu hamil $(0,006<0,05)$. Disarankan kepada Puskesmas Sangkunur agar rutin memberikan sosialisasi kepada ibu hamil tentang pentingnya melakukan kunjungan pemeriksaan kehamilan guna mendapatkan pelayanan asuhan antenatal sehingga ibu hamil dapat berkunjung ke tempat pelayanan kesehatan
\end{abstract}

Kata Kunci : Pengetahuan, Cakupan K4

\section{PENDAHULUAN}

Kehamilan merupakan suatu proses yang dialami oleh wanita di seluruh dunia. Masa kehamilan dimulai dari konsepsi sampai lahirnya janin, lamanya hamil normal adalah 280 hari (40 minggu atau 9 bulan 7 hari) dihitung dari hari pertama haid terakhir. Kehamilan dibagi dalam 3 triwulan yaitu triwulan pertama dimulai dari konsepsi sampai 3 bulan, triwulan kedua dimulai dari 4 bulan sampai 6 bulan, triwulan ketiga dari bulan 7 sampai 9 bulan. $^{(1)}$

Antenatal Care (ANC)/Asuhan antenatal adalah suatu program yang terencana berupa observasi, edukasi dan penanganan medik pada ibu hamil, untuk memperoleh suatu proses kehamilan dan persalinan yang aman dan memuaskan. Kunjungan ANC sebaiknya dilakukan sekurang-kurangnya 4 kali selama kehamilan yaitu K1 sampai dengan K4. ${ }^{(1)}$

Upaya kesehatan ibu dan anak adalah upaya bidang kesehatan terkait pelayanan dan pemeliharaan ibu hamil, bersalin, menyusui, bayi, dan anak balita serta anak prasekolah. Seorang ibu berperan penting dalam pertumbuhan bayi dan perkembangan anak. Gangguan kesehatan yang dialami ibu hamil mempengaruhi kesehatan janin sampai masa anak-anak. ${ }^{(2)}$

Angka Kematian Ibu (AKI) tahun 2015 di negara-negara Asia Tenggara seperti Malaysia 

Vol. 16 No. 3 September - Desember 2021

(40/100.000 kelahiran hidup), Brunei Darussalam (23/100.000 KH), Vietnam (54/100.000 KH), serta Singapore (10/100.000 KH). Dibandingkan dengan negara-negara Asia Tenggara, Angka kematian ibu (AKI) di indonesia masih cukup tinggi yaitu $\left(126 / 100.000 \mathrm{KH} .{ }^{(2)}\right.$

Data Kemenkes RI (2017) melaporkan terjadi penurunan cakupan K4 yaitu dari $86.85 \%$ pada tahun 2013 menjadi $86.70 \%$ pada tahun 2014, tetapi tahun 2015 mengalami peningkatan menjadi $87.48 \%$. Tahun 2016 kembali terjadi penurunan menjadi $85.35 \%$, tetapi angka ini telah mencapai target Renstra Kementerian Kesehatan tahun 2016 yaitu sebesar 74.00\%. Provinsi yang telah mencapai cakupan K4 tertinggi adalah Provinsi Nusa Tenggara Barat (97.78\%), sedangkan provinsi terendah dalam pencapaian cakupan K4 adalah Maluku Utara (21.00\%). ${ }^{(2)}$

Angka kematian ibu melahirkan di Indonesia saat ini tergolong masih cukup tinggi dibandingkan negara-negara lain, padahal Angka Kematian Ibu (AKI) dan angka kematian bayi (AKB) menjadi salah satu indikator penting dalam menentukan derajat kesehatan masyarakat. Berdasarkan Survei Demografi dan Kesehatan Indonesia (SDKI) tahun 2012, angka kematian ibu (yang berkaitan dengan kehamilan, persalinan, dan nifas) sebesar 359 per 100.000 kelahiran hidup. Angka ini masih cukup tinggi apalagi jika dibandingkan dengan negara-negara tetangga. ${ }^{(2)}$

Cakupan pelayanan kesehatan ibu hamil dapat dinilai dengan menggunakan indikator Cakupan K1 dan K4. Cakupan K1 adalah jumlah ibu hamil yang telah memperoleh pelayanan antenatal care pertama kali oleh tenaga kesehatan, dibandingkan jumlah sasaran ibu hamil di satu wilayah kerja pada kurun waktu satu tahun. Sedangkan Cakupan K4 adalah jumlah ibu hamil yang telah memperoleh pelayanan antenatal care sesuai dengan standar paling sedikit 4 kali sesuai jadwal yang dianjurkan, dibandingkan jumlah sasaran ibu hamil di satu wilayah kerja pada kurun waktu satu tahun. Indikator tersebut memperlihatkan akses pelayanan kesehatan terhadap ibu hamil dan tingkat kepatuhan ibu hamil dalam memeriksakan kehamilannya ke tenaga kesehatan. ${ }^{(2)}$

Data Profil Kesehatan Indonesia Tahun 2017 menunjukkan bahwa cakupan K4 di Indonesia pada tahun 2015 sebesar 87,48\% dan mengalami penurunan pada tahun 2016 menjadi 85,35\% sedangkan pada tahun 2017 mengalami penurunan kembali menjadi $85 \%$ padahal Kementerian Kesehatan RI memberikan target cakupan K4 sebesar 90\%. Penurunan angka cakupan K4 di Indonesia akan meningkatkan resiko kenaikan Angka Kematian Ibu (AKI) dan Angka Kematian Bayi ( AKB) . ${ }^{(2)}$

Data dari Dinas Kesehatan Propinsi Sumatera Utara tahun 2013, AKI maternal sebesar 268 per 100.000 kelahiran hidup. Hasil Sensus Penduduk 2010, AKI di Sumatera Utara sebesar 328 per 100.000 kelahiran hidup, angka ini masih cukup tinggi bila dibandingkan dengan angka nasional hasil Sensus Penduduk 2010 sebesar 259 per 100.000 kelahiran . ${ }^{(2)}$

Puskesmas Sangkunur merupakan salah satu Puskesmas yang ada di wilayah Kabupaten Tapanuli Selatan, dan merupakan Puskesmas dengan cakupan K4 yang cukup rendah. Berdasarkan data yang diperoleh di Puskesmas Sangkunur cakupan K4 pada tahun 2018 masih 44,93\% dan tahun 2019 mengalami kenaikan yang tidak signifikan yaitu menjadi $50,55 \%$. $^{(3)}$

Pelayanan kesehatan antenatal sangat penting dalam mengurangi kematian akibat persalinan jika dilakukan dengan jumlah dan frekuensi yang sesuai standar pelayanan antenatal care. Hal ini didukung oleh beberapa penelitian, seperti penelitian yang dilakukan oleh Kusuma R, pada tahun 2018 yang menunjukkan adanya hubungan yang bermakna antara faktor umur ( $p$ value $=0,003)$, jarak kehamilan $(p$ value $=0,013)$, pengetahuan $(p$ value $=0,001)$, media informasi ( $p$ value $=0,003)$, dukungan suami ( $p$ value $=$ $0,007)$ dan dukungan petugas kesehatan ( $p$ value $=0,002$ ) dengan cakupan kunjungan Antenatal Care (ANC) dengan cakupan kunjungan Antenatal Care (ANC) pada ibu hamil di wilayah kerja Puskesmas Klambu Kabupaten Grobogan. ${ }^{(4)}$

Hasil survey awal yang telah dilakukan oleh peneliti dengan 10 orang ibu hamil diperoleh bahwa dari 10 orang ibu hamil yang diwanwancarai terdapat 6 orang ibu yang tidak melakukan pemeriksaan kehamilan secara lengkap, dengan 4 orang berpendidikan SMA dan 2 orang berpendidikan SMP, sedangkan 4 orang ibu hamil lagi melakukan pemeriksaan kehamilan secara lengkap (melakukan kunjungan K1 dan K4) dengan 2 orang berpendidikan S1 dan 2 orang lagi berpendidikan SMA. Adapun alasan ibu hamil tidak melakukan pemeriksaan lengkap diduga disebabkan rendahnya pengetahuan 
dimana tingkat pendidikan rata-rata SMP dan SMA.

Hal ini ini membuat peneliti tertarik untuk melakukan penelitian tentang Hubungan Pengetahuan dengan Cakupan K4 pada ibu hamil di Puskesmas Sangkunur.

\section{METODE}

Jenis Penelitian ini merupakan penelitian survei analitik dengan menggunakan pendekatan cross sectional, untuk mengetahui hubungan pengetahuan dengan cakupan K4 pada ibu hamil. Penelitian ini dilaksanakan di Puskesmas Sangkunur Kabupaten Tapanuli Selatan pada bulan Maret s/d Mei 2020. Populasi dalam penelitian ini adalah seluruh ibu hamil trimester III akhir yang ada di wilayah kerja Puskesmas Sangkunur Kecamatan Angkola Sangkunur Kabupaten Tapanuli Selatan sebanyak 124 orang. Sampel dalam penelitian ini dilakukan dengan rumus slovin, sehingga diperoleh jumlah sampel 95 orang. Kemudian dianalisis dengan menggunakan tekhnik analisa univariat dan bivariat dengan menggunakan uji Chi-Squere.

\section{Hasil Penelitian}

Analisis Univariat

Tabel 1.

Analisis Bivariat

Tabel 3. Hubungan Pengetahuan dengan Cakupan K4 pada Ibu Hamil
Distribusi Frekuensi Berdasarkan Pengetahuan Responden di Puskesmas Sangkunur Tahun 2020

\begin{tabular}{lccc}
\hline No & Pengetahuan & $\mathrm{N}$ & $\%$ \\
\hline 1. & Kurang & 43 & 45.3 \\
2. & Baik & 52 & 54.7 \\
\hline & Total & $\mathbf{9 5}$ & $\mathbf{1 0 0 . 0}$ \\
\hline
\end{tabular}

Berdasarkan tabel diatas, responden berpengetahuan baik sebanyak 52 responden (54.7\%) dan berpengetahuan kurang sebanyak 43 responden $(45.3 \%)$.

\section{Tabel 2}

Distribusi Frekuensi Berdasarkan Cakupan K4 di Puskesmas Sangkunur Tahun 2020

\begin{tabular}{lccc}
\hline No & Cakupan K4 & $\mathrm{N}$ & $\%$ \\
\hline 1. & Mencukupi & 34 & 35.8 \\
2. & Tidak & 61 & 64.2 \\
& Mencukupi & & \\
\hline & Total & $\mathbf{9 5}$ & $\mathbf{1 0 0 . 0}$
\end{tabular}

Berdasarkan tabel diatas, mayoritas cakupan K4 responden tidak mencukupi sebanyak 61 responden $(64.2 \%)$ dan minoritas cakupan $\mathrm{K} 4$ responden mencukupi sebanyak 34 responden $(35.8 \%)$.

\begin{tabular}{|c|c|c|c|c|c|c|c|c|}
\hline \multirow{3}{*}{ No } & \multirow{3}{*}{ Pengetahuan } & \multicolumn{4}{|c|}{ Pemeriksaan K4 } & & & \multirow{3}{*}{$P$} \\
\hline & & \multicolumn{2}{|c|}{ Sesuai } & \multicolumn{2}{|c|}{ Tidak sesuai } & \multicolumn{2}{|c|}{ Jumlah } & \\
\hline & & $\mathbf{N}$ & $\%$ & $\mathbf{N}$ & $\%$ & $\mathbf{N}$ & $\%$ & \\
\hline 1. & Kurang & 8 & 18.6 & 35 & 81.4 & 43 & 100 & \\
\hline 2. & Baik & 30 & 57.7 & 22 & 42.3 & 52 & 100 & 0.006 \\
\hline & Total & 38 & 40.0 & 57 & 60.0 & 95 & 100 & \\
\hline
\end{tabular}

Berdasarkan hasil penelitian hubungan pengetahuan dengan cakupan K4 pada ibu hamil, hasil uji statistik dengan Chi_Square menunjukkan ada hubungan pengetahuan dengan cakupan K4 pada ibu hamil di Puskesmas Sangkunur, dengan nilai probabilitas $(p)=0,006$ $<0,05$.

\section{PEMBAHASAN}

\section{Hubungan Pengetahuan dengan Cakupan K4 pada Ibu Hamil}

Berdasarkan hasil penelitian, responden berpengetahuan baik sebanyak 52 responden $(57.7 \%)$ dan berpengetahuan kurang sebanyak 43 responden $(45.3 \%)$. Hasil penelitian hubungan pengetahuan dengan cakupan K4 pada ibu hamil, hasil uji statistik dengan Chi_Square menunjukkan ada hubungan pengetahuan dengan 
cakupan K4 pada ibu hamil di Puskesmas Sangkunur, dengan nilai probabilitas $(\mathrm{p})=0,006<$ 0,05 .

Penelitian ini sejalan dengan dengan hasil penelitian Meldafia I, 2016 tentang tingkat pengetahuan dengan kunjungan K4 Antenatal Care di Puskesmas Lubuk Kilangan Padang, berdasarkan uji analisis statistik didapatkan nilai $\mathrm{p}=0,00(\mathrm{p}<0,05)$ yang menunjukkan bahwa terdapat hubungan antara tingkat pengetahuan ibu hamil dengan K4 Antenatal Care. ${ }^{(5)}$

Hasil penelitian Dian P 2013, berdasarkan hasil tabulasi silang antara tingkat pengetahuan dengan sikap ibu hamil

dalam melakukan kunjungan K4 bahwa sebagian besar ibu hamil (43\%) memiliki tingkat pengetahuan kurang dan sikap ibu hamil positif. Dan hampir seluruhnya ibu hamil (80\%) memiliki tingkat pengetahuan kurang dan sikap ibu hamil negatif. Serta sebagian kecil ibu hamil $(28,5 \%)$ memiliki tingkat pengetahuan baik dan sikap ibu hamil positif. Dari hasil uji statistik Median didapatkan nilai sig 0,026, yang artinya ada hubungan antara tingkat pengetahuan dengan sikap ibu hamil dalam melakukan kunjungan K4 di desa Kalimo'ok Kecamatan Kalianget Kabupaten Sumenep. ${ }^{(6)}$

Hasil penelitian Rizki ML, Melisa F, Dita WP, menunjukkan ada hubungan yang signifikan antara pengetahuan responden tentang ANC dengan kunjungan $\mathrm{K} 4$ antenatal care di wilayah kerja Puskesmas Kalampangan. ${ }^{(7)}$.

Menurut asumsi peneliti upaya yang telah dilakukan Puskesmas Sangkunur untuk tercapainya K4 salah satunya dengan pelaksanaan kelas ibu hamil, dimana menurut kemenkes 2011 kelas ibu hamil adalah kelompok belajar ibu-ibu hamil dengan umur kehamilan antara 4 minggu s/d 36 minggu (menjelang persalinan) dengan jumlah peserta maksimal 10 orang, dikelas ini ibuibu hamil akan belajar bersama, diskusi dan tukar pengalaman tentang kesehatan ibu dan anak (KIA) secara menyeluruh dan sistematis serta dapat dilaksanakan secara terjadwal dan berkesinambungan.

Dengan kelas ibu hamil ini bertujuan meningkatkan pengetahuan, merubah sikap dan perilaku agar memahami tentang kehamilan. Jumlah pertemuan kelas ibu hamil minimal $4 x$ selama hamil atau sesuai kesepakatan dengan tenaga kesehatan. Tetapi peneliti melihat bahwa antusias ibu hamil untuk melakukan pertemuan sangatlah minim hanya dihadiri 5 orang ibu hamil setiap sekali pertemuan, padahal ibu hamil dijemput kerumah menuju tempat pertemuan akan tetapi dengan berbagai alasan ibu hamil tidak dapat menghadirinya yaitu tidak ada waktu dan malas, ibu hamil seorang pekerja,dan berkunjung ke tempat saudara sehingga pertemuan untuk kelas itu hamil tidak maksimal.

\section{KESIMPULAN}

Ada hubungan pengetahuan dengan cakupan K4 pada ibu hamil di Puskesmas Sangkunur, nilai probabilitas $(\mathrm{p})=0,006<0,05$

\section{SARAN}

1. Diharapkan kepada Puskesmas Sangkunur melakukan inovasi baru agar kelas ibu hamil ramai dikunjungi ibu hamil dan menginformasikan ke Lintas Sektor agar dapat memberikan perubahan perilaku masyarakat khusus nya ibu hamil.

2. Diharapkan kepada Dinas Kesehatan Kabupaten Tapanuli Selatan untuk dapat terus meningkatkan upaya promosi kesehatan terutama mengenai kunjungan ANC terpadu dengan minimal kunjungan 4 kali selama masa kehamilan, guna mencapai indikator cakupan pelayanan K4.

3. Bagi peneliti selanjutnya disarankan untuk melakukan penelitian dengan menambah variable yang berasal dari faktor pemungkin dan faktor penguat terhadap kunjungna $\mathrm{K} 4$ pada ibu hamil agar semakin banyak informasi yang diperoleh tentang kunjungna $\mathrm{K} 4$ pada ibu hamil.

\section{DAFTAR PUSTAKA}

1. Prawirohardjo, Sarwono, Pelayanan Kesehatan Maternal dan Neonatal. 2016. Jakarta : YBP - SP.

2. Kemenkes RI. Data dan informasi Profil Kesehatan Indonesia Tahun 2017. Pusdatin Kementerian Kesehatan.Jakarta. 
https://pusdatin.kemkes.go.id/resources/d ownload/pusdatin/profil-kesehatanindonesia/Data-dan-Informasi_ProfilKesehatan-Indonesia-2017.pdf

3. Profil Puskesmas Sangkunur Tahun 2019.

4. Kusuma R, Hubungan Pengetahuan dan Sikap Ibu Hamil tentang Antenatal Care dengan Kunjungan K4.2018. Jurnal Departement of Nursing, Baiturrahim School of Health Science. volume 03, no. 01, juli 2018: 24-32

5. Meldafia I, Hubungan Tingkat Pengetahuan dan Sikap Ibu Hamil dengan Kunjungan K4 Antenatal Care di Wilayah Kerja Puskesmas Lubuk Kilangan Padang. 2016. Jurnal kesehatan medika saintika volome 8 nomor1|http://jurnal.syedzasaintika.ac.id

6. Dian P, Hubungan Tingkat Pengetahuan Dengan Sikap Ibu Hamil Dalam Melakukan Kunjungan K4 Di Desa Kalimo'ok Kecamatan Kalianget Kabupaten Sumenep. 2013. Jurnal Program Studi Kebidanan jurnal kesehatan wirarajamedika.ac.id

7. Rizki ML, Melisa F, Dita WP. Hubungan Pengetahuan Dan Sikap Ibu Hamil Terhadap Kepatuhan Kunjungan K4 antenatal care di wilayah kerja puskesmas kalampangan Kota Palangka Raya. 2018. Jurnal Dinamika Kesehatan, Vol 9 No. 2 Desember 2018. 